\section{NOMENCLATURE PROBLEMS OF THE APPLIED BIOLOGIST}

\begin{abstract}
$\mathrm{A}^{\mathrm{T}}$
T a meeting of the Association of Applied place on practical problems of botanical and zoological nomenclature. Dr. J. Ramsbottom (Department of Botany, British Museum (Natural History)), in opening the discussion, referred to the common but erroneous idea that systematists have as their main object the upsetting of established names. Paradoxical though it may seem, changes in scientific names are designed to achieve stability. The principle of priority is that the first validly published name for an organism is the one to be used. This principle is perfectly sound in theory, but its practical application is complicated by the fact that many names published in obscure journals are not rediscovered until years afterwards, when well-known names may have to be rejected in their favour.

The International Rules of Botanical Nomenclature permit of the conserving of well-established generic names under certain conditions; but proposals to conserve specific names have always been defeated in the past and are not likely to be accepted by any International Botanical Congress in the future. The conservation of a specific name would mean fixing the rank and genus of the plant concerned, regardless of subsequent research, which is incompatible with scientific taxonomy. On the other hand, a suggestion emanating from the Royal Horticultural Society to legalize the rejection of certain specified names may contain the germ of an idea which is workable and would achieve the same result in practice. The not unnatural desire of the economic botanist to have one name and one name only for any one plant is likewise incompatible with progress in taxonomy. A plant can have as many names as genera in which it has been placed. Genera may be split. up into smaller genera or may be combined into larger genera ; or a species may be reduced in rank to that of a variety. Homonyms provide another reason for change: sometimes it is found that the name of a well-known plant has previously been applied to some other species; a change must therefore be made.
\end{abstract}

To try to fix specific names it has often been proposed that standard lists of conserved names should be prepared. But it should be understood that no standard list can prevent changes of name caused by changes in classification.

Mr. G. R. Bisby (Imperial Mycological Institute) pointed out that mycologists have done little to deal with their special problems of nomenclature; the two articles of the International Rules applying particularly to fungi are still ambiguous and are variously interpreted, and no generic name of a fungus has yet been conserved. He suggested that there should be a permanent executive committee, with changing personnel, for the nomenclature of fungi; that this committee or some other should produce a shorter special code for mycological nomenclature, to apply under the International Rules; that users of names (including plant pathologists and various kinds of mycologists) should be given a chance to vote on proposals, such as the conservation of a few specific epithets, which affect them greatly; that specific epithets of fungi be decapitalized; and that the conservation of generic names be effected when necessary and desirable.
Mr. B. J. Rendle (Forest Products Research Laboratory) gave an account of what has been done in recent years towards stabilizing the names of timber trees. Workers in forestry and wood technology have suffered much inconvenience from changes in the names of common trees, most of them due to the application of the priority rule. Some bodies have found it expedient to fix certain well-known botanical names for their own use, in contravention of the International Rules. The reasons for doing so can be appreciated when it is remembered that trees are often cited by their botanical names in legislation, forest department regulations, contracts for timber concessions, specifications for timber and so on. A measure of stability has been achieved by the Empire Forestry Association and the British Standards Institution in drawing up a list of standard trade names of timbers with their correct botanical names. Over a period of about fifteen years this list has been repeatedly checked and revised, and is now as nearly correct as it can be.

It may not be generally known that the Sixth International Botanical Congress, in 1935, as a practical alternative to conserving specific names, adopted a motion "That an International Committee be appointed to draw up a list of names of economic plants according to the International Rules and that this list may remain in use for a period of ten years". It is understood that the work of this Committee was proceeding very satisfactorily until the outbreak of war; but since then it has been practically impossible to carry on, and much still remains to be done before the list is ready for publication.

Mr. A.' Roebuck (Midland Agricultural College, Sutton Bonington) spoke feelingly from the point of view of an advisory agricultural entomologist. $\mathrm{He}$ deplored the frequent changes in the names of insects. To the field-worker it is the insect that matters; the name is of importance merely as a label or means of designation, so that one man can understand what another is talking or writing about. He quoted as an example a common insect pest which, in the course of a few years, has been placed in four different genera; much confusion has been caused to farmers in consequence. Genera are sometimes sub-divided on what appear to be insufficient grounds ; for example, when three insects are difficult to separate into species, it seems unreasonable to place them in different genera. As a practical sugg stion for stabilizing the names of economic insects, Mr. Roebuck advocated the use of English names for British insects, and suggested the preparation of a standard list giving the common names and the corresponding scientific names, the latter to be revised from time to time to keep pace with changes in taxonomic entomology.

Dr. I. Thomas (School of Agriculture, University College of North Wales), while supporting the claim that stability in nomenclature is incompatible with progress in taxonomy, was in favour of a standard list of Latin names of insects for the convenience of economic entomologists, provided that such a list were brought up to date at intervals of ten or twenty years. Periodic revision would provide the opportunity of asking the International Commission on Zoological Nomenclature to suspend the rules in cases where greater confusion than uniformity would result from a change. As an example of the confusion which may be caused by strict application of the law of priority, Dr. Thomas described what has recently happened in the family Aphidæ. 
According to Hille Ris Lambers ${ }^{1}$ the potato aphis Macrosiphum solanifolii (Ashmead, 1882) should now be designated $M$. euphorbioe (Thomas, 1878). Unfortunately, Theobald stated that the species solanifolii Ash. was identical with gei (Koch, 1855) and the latter name, as a result of the application by Theobald of the law of priority, became well known in the literature. In all, Ris Lambers gives a list of twentyfour synonyms for this aphis. If it were possible easily to have the rules of nomenclature suspended in this instance, probably all economic entnmologists would like to see the name solanifolii established. As a result of a discussion on the law of priority the Royal Entomological Society set up a Committee on Generic Nomenclature, but its lists are sometimes not accepted even by the authors of the lists themselves.

Entomological literature is still suffering from the effects of inadequate descriptions of proposed new species. Some of the deseriptions given even in present-day literature are totally inadequate. All such work has to be sifted by the bona fide systematist, and it would considerably lighten his labours if something could be done to establish a minimum standard for publications.

Mr. Francis Hemming (secretary to the International Commission on Zoological Nomenclature) described the working of the International Code of Zoological Nomenclature. This was drawn up primarily by workers in systematic zoology in order to meet the needs of workers in that field, and unanimity was only achieved by placing a greater stress on the law of priority than had previously been intended. The International Code won a rapid acceptance among systematic zoologists, but owing to the .rigidity of Article 25 (Law of Priority) difficulties were soon encountered, since the application of that Article led to well-known and well-established generic names being replaced by older but less well-known names. Objection was taken to such changes not only by numerous systernatic zoologists but also by workers in applied biology, who argued that, whatever rules of nomenclature systematists might adopt for their own purposes, those rules should be such as to secure a reasonable degree of stability for important names widely used in the applied field.

The International Congress tried to meet this criticism at a meeting held at Graz in 1910, in which it was agreed in principle to establish an Official List of Generic Names in Zoology, with their type species. It was hoped that in this way it would be demonstrated that the Berlin Code of 1901 would secure stability for a wide range of important names, and therefore that the area of disagreement would be greatly narrowed. In 1913 at Monaco, the International Congress again considered this problem and decided to settle it by the grant (subject to certain safeguards) of plenary powers to the International Commission on Zoological Nomenclature to suspend the rules as applied to any given case where, in the judgment of the Commission, the strict application of the rules would clearly result in greater. confusion than uniformity. It will be seen, therefore, that, as regards zoological names of importance either to workers in the applied field or to workers in systematic zoology, two valuable and important instruments have been placed in the hands of the International Commission in order to assist in the stabilizing of zoological nomenclature.

The International Commission is anxious to extend the Official List so as to include the names of all the most important genera in the animal kingdom.
Arrangements are now being made for the early publication of the Official List, giving full bibliographical particulars relating to the names (between six and seven hundred in number) which have so far been admitted. The International Commission is hopeful that the publication of the Official List in this way will demonstrate the value of securing the admission of generic names to the list, and will stimulate specialists in various fields to submit proposals for further additions to the List. Applied biologists can be assured that, where any group of workers notifies the International Commission regarding names which they would like to see stabilized by admission to the Official List, the Commission, for its part, will do everything possible to meet their wishes in this matter. Here and there cases will no doubt arise where it will be found impossible to place some well-known name on the Official List without the Commission first suspending the rules in order to validate that name by suppressing 'some earlier name, or by fixing as the type of the genus some species other than that which is the type under the International Code. Where there are such cases, the sooner they are brought out into the open and settled once and for all, the better for all concerned.

In the general discussion which followed the more formal contributions, several speakers returned to the suggestion that for certain purposes common names are more convenient and more easily stabilized than scientific names. Standard lists of trade or common names, or more compendious works of reference such as the British Pharmacopoeia, must necessarily give the corresponding scientific names in order to fix the identity of the organisms concerned; the scientific nomenclature can be kept up to date by periodic revision without affecting the common names. It was pointed out that although it is impracticable permanently to stabilize scientific names, the risk of confusion can be minimized by following some standard work of reference. It is open to any author of a paper or text-book, for example, to say in his introduction that he is using the names in the $n$th edition of such and such a standard work.

The discussion served to clarify the distinction between name-changes due to advances in taxonomy and those due to conventions such as the law of priority. No responsible body of biologists would seriously propose to limit improvements in classification by permanently stabilizing scientific names, though many would wish to see more careful consideration on the part of taxonomists before upsetting established names by minor changes in the rank of important economic plants and animals. Admittedly, the herbarium worker, dealing with very large numbers of specitmens and continually striving towards the ideal system of classification, does not always appreciate the trouble which name-changes may cause to economic botanists concerned with a limited number of species. At the other extreme, the applied biologist, and still more the farmer or timber merchant trying to take an intelligent interest in the scientific aspect of his work, often fails to realize that a name is something more than a label, and condernns the name-changers as being uncompromising, academic and out of touch with realities.

There is a strong case to be made against namechanges which do not signify any progress in taxonomy, as when the resurrection of a prior name invalidates a well-known and old-established name. Botanists and zoologists attending the meeting were able to compare the merits of the international codes of 
nomenclature for the two sciences with respect to this problem. The Botanical Rules provide for the conservation of generic names to avoid disadvantageous changes in nomenclature which might result from strict application of the Rules, but they do not permit of conserving specific epithets. Zoologists are perhaps more fortunate in that their standing International Commission on Nomenclature has plenary powers to suspend the rules in cases where their strict application would result in greater confusion than uniformity. Several suggestions were put forward by botanists to restrict changes due to the principle of priority, either by introducing a time limit for the reviving of an old name or by amending the rules so as to allow of the rejection of names which are clearly undesirable. A formal proposal that the Council of the Association of Applied Biologists should examine the question was carried without dissent.

B. J. RENDLE.

${ }^{1}$ Hille Ris Lambers, D., Temminckia, 4, 84 (1939).

\section{GEOCHEMISTRY IN THE U.S.S.R.}

\section{By S. I. TOMKEIEFF}

\author{
King's College, Newcastle upon Tyne
}

$\mathrm{T}$ HE term 'geochemistry', like many other scientific terms, has a variable connotation. If geochemistry means simply the chemical study of the earth or parts of the earth, then geochemistry must be as old as chemistry itself, and dates from the attempts of Babylonian and Egyptian metal-workers and potters to understand the nature and properties of their materials. If, on the other hand, geochemistry is not only that, but something more, namely, an attempt to understand the distribution of chemical elements in the different parts of the earth, the migration of chemical elements and the laws of their combinations in the process of mineral formation, then geochemistry is indeed a young science. ' This is why the Russian geochemists claim that geochemistry is the science of the twentieth century. In saying that, they imply that science does not consist of a mere collection of data, but involves also theories and hypotheses which link up the data to form an organized whole; that a real science involves a definite mental technique in handling problems, setting up new points of view, and, in general, marshalling the results of experience. According to the Russian men of science, geochemistry is now passing from the stage of the 'data of geochemistry' to the 'science of geochemistry'; and from being, a mere handmaid of mineralogy, petrology and economic geology, it is emerging as an autonomous science with its own problems, scope and methods.

A determined attempt to establish an autonomous science of geochemistry was made by Vernadsky, Fersman, Goldschmidt and Niggli, to mention only the four most prominent workers in this field. It is in Russia that geochemistry has taken deepest root, no doubt because of the widespread search for economic minerals and the scientific renaissance during the last two decades. Unfortunately, the intellectual isolation of the U.S.S.R. and the language barrier has made it difficult for scientific workers in other countries to become really acquainted with this movement.

The old descriptive mineralogy and descriptive petrology, which made such great strides during the last century, were predominantly static sciences.
Many attempts at a genetic approach were made before Vernadsky, but perhaps it is to him that we owe its most forcible expression. He began in 1890 to break new ground in his lectures at the University of Moscow, and developed this work in his book on descriptive mineralogy ${ }^{1}$, which began to appear in parts in 1908 and is still unfinished; for the surge of new ideas in the mind of the author led him to embark in 1925 on yet another serial work, the history of minerals ${ }^{2}$. Unfortunately, these books are not only left unfinished, but also their subject-matter is presented in such an inchoate form that they are di iricult to follow. However, the author has managed to present his ideas more coherently and in application to more restricted problerns in a book published in Russian, German and French ${ }^{3}$. In it we see a definite attempt to build a new lgeochemistry on the basis of the old mineralogy-an attempt full of daring ideas and schemes. It is a book that may shock an orthodox mineralogist and leave him bewildered and dazed. In spite of this, however, the book is very vivid and stimulating, and it suggests many new problems which, if followed up, may lead to some new fields of science. Vernadsky's next book ${ }^{4}$ is even more daring, for it deals with that still more complex realm, the biosphere, the sphere of life, full of complexities and change. By publishing this book, Vernadsky stimulated the study of what he called 'biogeochemistry'-the study of the chemical composition of the living matter in relation to the organically formed rocks. A biogeochemical laboratory was established in the U.S.S.R. and it soon became the thriving centre of a new research school.

Vernadsky's younger contemporary, Fersman, began his lectures on geochemistry in Moscow's People University in 1912. By that time he had already conceived the idea of a book which would not only include all the data of geochemistry, but also present a synoptic view of the whole subject. It is important to note here that Fersman, like Vernadsky, being a first-class mineralogist, made the approach to geochemistry from the side of mineralogy. His main interest at that time was concentrated on regional mineralogy, or as he called it 'topomineralogy', and in 1922 he published the first part of his ambitious work on the geochemistry of Russia ${ }^{5}$, which was left unfinished under the stress of the new ideas which emerged from it. In this book he used regional mineralogy only as a basis for a superstructure of geochemistry. His mineral assemblages became genetic types, mineral provinces became geochemical provinces, and these in their turn were incorporated into geospheres, the whole being linked up into unending genetic cycles. In this way genetic mineralogy and genetic petrology became incorporated into the all-embracing geochemistry. Not satisfied with geospheres and the unknown centrosphere, Fersman overflowed into the cosmos, incorporating the sun, the stars and the meteorites, merging geochemistry into cosmochemistry. These ideas were fully developed by him in his next book, published in $1923^{6}$.

Not only interested in the distribution of the chemical elements in the geospheres and in the cosmos, Fersman made an attempt to find the causes of such a distribution. Following up the guiding ideas of De Launay and Goldschmidt, he tried to connect up the distribution of the chemical elements and their atomic structure, first in a series of papers and later in a monumental work of more than 1,500 pages entitled "Geochemistry"? "The main body of this work is contained in the first three volumes; the 